\title{
PENGEMBANGAN APLIKASI KALKULATOR PENGHITUNG LUMINANSI BERBASIS ANDROID
}

\author{
Dyah Vitalocca ${ }^{1}$, Andi Ahmad Badaruddin ${ }^{2}$ \\ ${ }^{1}$ Pendidikan Teknik Informatika dan Komputer, Universitas Negeri Makassar \\ Dyah_vitalocca@unm.ac.id \\ ${ }^{2}$ Pendidikan Teknik Elektro, Universitas Negeri Makassar \\ andiahmad376@gmail.com
}

\begin{abstract}
ABSTRAK
Penelitian ini adalah penelitian pengembangan perangkat lunak yang bertujuan untuk menghasilkan aplikasi Kalkulator Penghitung Luminansi Berbasis Android sebagai media informasi luminansi. Pengujian dilakukan dengan menggunakan standar ISO 25010 yang terdiri dari aspek functionality, portability, efficiency, maintainability dan usability. Model pengembangan yang digunakan dalam dalam penelitian ini adalah prototyping dengan tahapan : pengumpulan kebutuhan, membangun prototypinng, pengkodean sistem, menguji sistem, evaluasi sistem, dan menggunakan sistem. Aplikasi dibangun menggunakan software Android Studio. Data dikumpulkan dengan menggunakan teknik wawancara, angket dan dokumentasi. Berdasarkan hasil penelitian dihasilkan sebuah aplikasi yang dapat digunakan sebagai media informasi luminansi dan cara menentukan nilai luminansi yang bersifat offline. Berdasarkan hasil pengujian ISO 25010 diperoleh hasil : a) pengujian aspek functionality menggunakan skala gutman dengan presentase $100 \%$ dan telah memenuhi aspek functionality, b) pengujian aspek efficiency dengan menggunakan Cloud.BitBar aplikasi telah memenuhi berdasarkan syarat litle eye; c) pengujian aspek portability pada beberapa jenis smartphone dan versi Android yang berbedadapat berjalan baik tanpa kendala; d) pengujian aspek maintainability aplikasi di anggap mudah untuk diperbaiki dan akan memberikan respon ketika ada kesalahan berdasarkan koding software Android Studio; e) pengujian aspek usability kepada 20 orang responden diperoleh presentase 95\% atau 19 responden memberi penilaian sangat baik dan $5 \%$ atau 1 responden memberi penilaian baik, sehingga untuk keseluruhan tanggapan responden diperoleh nilai rata-rata $90 \%$ dan berada pada kategori sangat baik.
\end{abstract}

Kata Kunci: Android, Kalkulator, Luminansi

\section{DEVELOPMENT OF ANDROID-BASED LUMINANCE CALCULATOR APPLICATION}

\begin{abstract}
This research is a software development research that aims to produce an Android-Based Luminance Calculator application as a medium for luminance information. The test is carried out using the ISO 25010 standard which consists of aspects of functionality, portability, efficiency, maintainability and usability. The development model used in this research is prototyping with the following stages: gathering requirements, building prototyping, coding the system, testing the system, evaluating the system, and using the system. The application is built using the Android Studio software. Data were collected using interview techniques, questionnaires and documentation. Based on the results of the research, an application that can be used as a medium for luminance information and a way to determine the luminance value is obtained is offline. Based on the results of the ISO 25010 test, the results obtained are: a) testing the functionality aspect using the gutman scale with a percentage of $100 \%$ and has met the functionality aspect, $b$ ) testing the efficiency aspect using Cloud.BitBar the application has met the little eye requirements; $c$ ) testing of portability aspects on several types of smartphones and different versions of Android can run well without any problems; $d$ ) testing the maintainability aspect of the application is considered easy to repair and will respond when there is an error based on the Android Studio software coding; e) testing usability aspects to 20 respondents obtained a percentage of $95 \%$ or 19 respondents gave a very good rating and $5 \%$ or 1 respondent gave a good rating, so that for the overall respondents' responses an average value of $90 \%$ was obtained and was in the very good category.
\end{abstract}

Keyword: Android, Calculator, Luminance 


\section{PENDAHULUAN}

Pencahayaan atau penerangan merupakan salah satu hal penting yang sangat dibutuhkan oleh manusia. Penerangan alami berasal dari cahaya matahari yang tersedia hanya pada pagi sampai sore hari. Sumber pencahayaan lsitrik merupakan sumber cahaya yang paling umum dan digunakan secaa luas. Pemanfaatan energi listrik sebagai sumber cahaya dilakukan melalui konversi energi. Lampu merupakan sumber cahaya yang memanfaatkan konversi energi listrik menjadi energi cahaya.

Pencahayaan merupakan jumlah penyinaran pada suatu bidang kerja yang diperlukan untuk melaksanakan kegiatan secara efektif [1]. Pencahayaan yang memadai akan memberikan kesan pemandangan yang baik dan keadaan lingkungan yang menyegarkan. Pemahaman akan pencahayaan yang baik akan memudahkan seseorang untuk menentukan sumber pencahayaan yang akan digunakan agar nyaman saat bekerja [2]. Sistem pencahayaan tidak hanya didasarkan pada besarnya intensitas cahaya yang dimiliki oleh suatu sumber cahaya, tetapi mempertimbangkan berbagai macam faktor yang mempengaruhi pemanfaatan penerangan. Sebagai contoh, sumber cahaya yang terlalu terang akan menyilaukan mata, sementara sumber cahaya yang redup akan melelahkan mata.

Secara umum pedoman yang diterbitkan oleh BSN tersebut bertujuan untuk memperoleh sistem pencahayaan dengan pengoperasian yang optimal sehingga penggunaan energi yang lebih efisien tanpa harus mengurangi dan atau mengubah fungsi bangunan, kenyamanan dan produktivitas penghuni serta mempertimbangkan aspek ramah lingkungan dan biaya. Pedoman tersebut dibuat sehingga tidak ada perbedaan dari pihak yang terlibat dalam perencanaan, pembangunan, pengoperasian dan pemeliharaan bangunan gedung agar penggunaan energi lebih efisisen. Sumber pencahayaan yang digunakan masyarakat sangat beragam. Yaitu, SNI Konversi Energi pada Sistem Pencahayaan yang diatur untuk meningkatkan efisiensi energi juga untuk mengurangi efek buruk terhadap manusia. Menurut [3], penerangan yang baik adalah penerangan yang memungkinkan tenaga kerja dapat melihat objek yang dikerjakannya secara jelas, cepat dan tanpa upaya-upaya yang tidak perlu. Pemanfaatan sumber informasi tersebut memiliki beberapa kekurangan, seperti kesulitan akses, kepraktisan dan kecepatan. Sumber informasi tersebut tidak menyediakan layanan yang dapat dengan mudah digunakan untuk mengevaluasi sistem pencahayaan.

Berdasarkan fakta tersebut di atas, diperlukan suatu sumber informasi yang lebih sederhana, mudah dipahami dan dapat diakses dengan mudah. Salah satu sumber informasi yang dapat mengakomodasi kebutuhan tersebut adalah aplikasi berbasis android. Lembaga riset digital marketing emarketer memperkirakan pada tahun 2018 jumlah pengguna aktif smartphone di Indonesia lebih dari100 juta orang [4]. Pengguna android berjumlah 95\% dari pengguna smartphone yang tersebar di Indonesia Angka tersebut menempatkan Indonesia sebagai pengguna aktif smartphone nomor lima di dunia. Pengembangan aplikasi ini juga lebih mengutamakan pengguna berbahas Indonesia mengingat aplikasi yang telah dikembangkan hanya berbahasa Inggris. Aplikasi yang direncanakan akan dikembangkan dengan offline sehingga akan selalu diakses dengan mudah.

Responden diambil berdasarkan keperluan peneliti yang ditarik secara proposif agar memperjelas kebutuhan masyarakat sebenarnya. Aplikasi tersebut digunakan sebagai pedoman untuk menentukan desain sistem pencahayaan sesuai kebutuhan yang mengacu pada Standar Nasional Indonesia. Berdasarkan uraian di atas, inovasi teknologi berbasis berbasis android sangat penting dilakukan. Pengembangan kalkulator penghitung luminansi berbasis android diharapkan mampu menyelesaikan berbagai macam masalah yang dihadapi masyarakat terkait dengan desain, pemasangan, pengoperasian dan evaluasi sistem pencahayaan dengan target user untuk masyarakat umum dan dapat digunakan pula untuk kontraktor listrik.

\section{METODE PENELITIAN}

Jenis penelitian ini adalah penelitian Research and Development atau $\mathrm{R} \& \mathrm{D}$ yaitu penelitian berdasarkan berdasarkan pengembangan aplikasi kalkulator sebelumnya yang dikembangkan dengan fitur-fitur penghitungan luminansi yang lebih lengkap dan lebih presisi dibandigkan aplikasi yang sebelumnya [5].

Pada penelitian ini, peneliti menggunakan model prototyping. Penelitian ini banyak digunakan untuk pengembangan perangkat lunak dengan 7 proses. Model prototyping memungkinkan pengembang dan pelanggan dapat saling berinteraksi selama proses pembuatan sistem. 


\section{HASIL DAN PEMBAHASAN}

\section{A. Hasil Penelitian}

Pada tahapan ini, pengembang mendefinisikan format dan kebutuhan keseluruhan perangkat lunak, mengidentifikasi semua kebutuhan, dan garis besar perangkat lunak yang akan dibuat. Pengembang melakukan analisa terhadap kebutuhan perangkat lunak yaitu berupa kuesioner offline yang disebar kepada masyarakat umum.

Berdasarkan hasil kuesioner yang disebar dan diisi oleh 30 orang responden yang ditarik secara porposif oleh peneliti guna mengetahui pendapat masyarakat mengenai dukungan aplikasi yang akan dikembangkan. Didapatkan kesimpulan bahwa aplikasi yang akan dikembangkan dianggap menarik dan akan memudahkan masyarakat untuk menyelesaikan masalahnya.

TABEL 1. PERBANDINGAN APLIKASI

\begin{tabular}{|c|c|c|c|c|}
\hline $\begin{array}{l}\mathbf{N} \\
\mathbf{o}\end{array}$ & $\begin{array}{ll}\text { Fitur } & \text { Yang } \\
\text { Dimiliki } & \end{array}$ & $\begin{array}{l}\text { Aplikasi I } \\
\text { (Luminious } \\
\text { Meter) } \\
\mathbf{6 , 7 m b}\end{array}$ & $\begin{array}{l}\text { Aplikasi } \\
\text { II (Light } \\
\text { Meter) } \\
6.7 \mathrm{Mb}\end{array}$ & $\begin{array}{l}\text { Aplikasi } \\
\text { Pengembang } \\
\text { (Kalkulator } \\
\text { Luminasi } 27 \\
\text { Mb) }\end{array}$ \\
\hline 1 & $\begin{array}{l}\text { Menghitung } \\
\text { Lumen sumber } \\
\text { cahaya }\end{array}$ & $\sqrt{ }$ & $\sqrt{ }$ & \\
\hline 2 & $\begin{array}{l}\text { Menggunakan } \\
\text { Internet }\end{array}$ & $\sqrt{ }$ & $\sqrt{ }$ & \\
\hline 3 & $\begin{array}{l}\text { komponen } \\
\text { Hardware } \\
\text { Handphone }\end{array}$ & $\sqrt{ }$ & $\sqrt{ }$ & $\sqrt{ }$ \\
\hline 4 & $\begin{array}{l}\text { Memiliki fitur } \\
\text { Jenis Ruangan }\end{array}$ & & $\sqrt{ }$ & $\sqrt{ }$ \\
\hline 5 & $\begin{array}{l}\text { Menghitung } \\
\text { kebutuhan } \\
\text { sesuai ruangan }\end{array}$ & & & $\sqrt{ }$ \\
\hline 6 & $\begin{array}{l}\text { Memiliki fitur } \\
\text { "jenis-jenis } \\
\text { lampu" }\end{array}$ & & & $\sqrt{ }$ \\
\hline 7 & $\begin{array}{l}\text { Memiliki "fitur } \\
\text { SNI } \\
\text { Penerangan", }\end{array}$ & & & $\sqrt{ }$ \\
\hline 8 & $\begin{array}{l}\text { Menggunakan } \\
\text { Bahasa } \\
\text { Indonesia } \\
\end{array}$ & & & $\sqrt{ }$ \\
\hline
\end{tabular}

Dari Tabel 1 dapat dilihat aplikasi sejenis yang memiliki kelebihan dan kekurangan masingmasing. Tahap mengkodekan sistem dilakukan untuk diterjemahkan ke dalam bahasa pemrograman yang sesuai. Bahasa pemrograman yang digunakan adalah bahas pemrograman Java yang ada pada software Android Studio.

Setelah dilakukan analisis, perancangan dan pembuatan aplikasi, maka dilanjutkan ke tahap berikutnya yaitu pengujian aplikasi. Pengujian aplikasi pada penelitian ini menggunakan ISO/IEC 25010 [6].

\section{Aspek Funcionality}

TABEL 2. PENGUJIAN FUNCIONALITY

\begin{tabular}{clll}
\hline Pertanyaan & $\begin{array}{l}\text { Skor } \\
\text { Total }\end{array}$ & $\begin{array}{l}\text { Skor } \\
\text { Maksimal }\end{array}$ & $\begin{array}{l}\text { Persentase } \\
(\%)\end{array}$ \\
\hline 1 & 2 & 2 & 100 \\
2 & 2 & 2 & 100 \\
3 & 2 & 2 & 100 \\
4 & 2 & 2 & 100 \\
5 & 2 & 2 & 100 \\
6 & 2 & 2 & 100 \\
7 & 2 & 2 & 100 \\
8 & 2 & 2 & 100 \\
9 & 2 & 2 & 100 \\
10 & 2 & 2 & 100 \\
11 & 2 & 2 & 100 \\
12 & 2 & 2 & 100 \\
13 & 2 & 2 & 100 \\
14 & 2 & 2 & 100 \\
15 & 2 & 2 & 100 \\
\hline Total & $\mathbf{3 0}$ & $\mathbf{3 0}$ & $\mathbf{1 0 0}$ \\
\hline
\end{tabular}

Berdasarkan perhitungan pada tabel diatas maka diperoleh presentrase $100 \%$ dari pengujian functionality. Nilai tersebut kemudian dikonversi ke data kualitatif dan berdasarkan skala penilaian produk media, dari skor presentase yang di dapat maka kualitas perangkat lunak dari sisi functionality dapat diterima dan sesuai dengan aspek functionality.

\section{Aspek Portability}

TABEL 3. PENGUJIAN PORTABILITY

\begin{tabular}{lllll}
\hline No & Pengujian & $\begin{array}{l}\text { Skor } \\
\text { Total }\end{array}$ & Berjalan & Gagal \\
\hline 1 & $\begin{array}{l}\text { Instalasi } \\
\text { Aplikasi Pada }\end{array}$ & 4 & 4 & 0 \\
& $\begin{array}{l}\text { Smartphone } \\
\text { Menjalankan } \\
\text { Aplikasi Pada }\end{array}$ & 4 & 4 & 0 \\
& Smartphone & & & \\
\hline & Total & 8 & 8 & 0 \\
\hline
\end{tabular}

Berdasarkan data di atas diketahui persentase penilaian dengan menggunakan rumus [7]:

Persentase $=\frac{\sum \text { Skor Hasil }}{\sum \text { Skor Total }} \times 100 \%$

Persentase $=\frac{8}{8} \times 100 \%=100 \%$

Berdasarkan perhitungan diatas diperoleh presentase "100\%" dari pengujian portability. Berdasarkan skala penilaian produk media dari skor presentase yang didapat maka kualitas aplikasi dari sisi portability mempunyai skala "sangat baik" dan telah memenuhi aspek portability. 


\section{Aspek Efficiency}

Analisis aspek Efficiency dapat diambil dari penggunaan memori dan CPU (Central Procecing Unit) dengan menggunakan alat analisis Cloud.Bitbar. Perencanaan peneliti yang menggunakan aplikasi gamebench diganti menjadi Cloud.BitBar dikarenakan penggunaan aplikasi gamebench yang sulit dijangkau oleh peneliti. Berikut adalah hasil pengujian Ram dan CPU pada aplikasi kalkulator penghitung luminansi berbasis android.

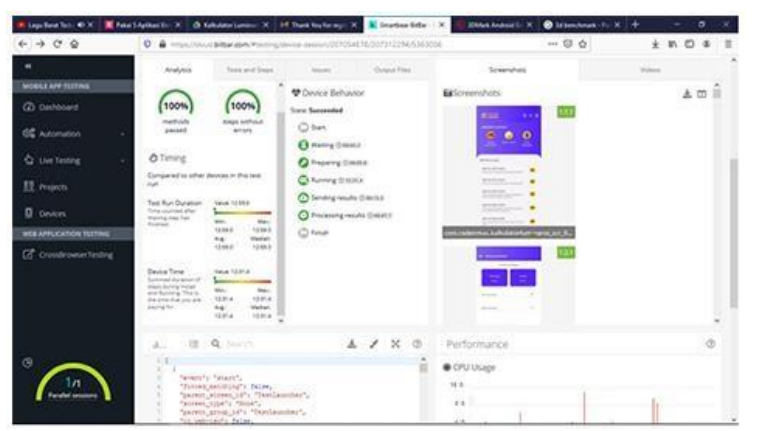

Penggunaan memory oleh aplikasi kalkulator penghitung luminansi berbasis android tidak terlalu besar. Menurut penelitian yang dilakukan Ridwan, 2018 kriteria dalam pengujian performance efficiency adalah penggunaan memori yang tidak sampai menyebabkan memory leak. Dan penilaian pada saat proses pengujian tidak ada peringatan error ataupun kegagalan pada setiap perintah. Adapun hasil dari pengujian memory bisa dilihat pada gambar berikut.

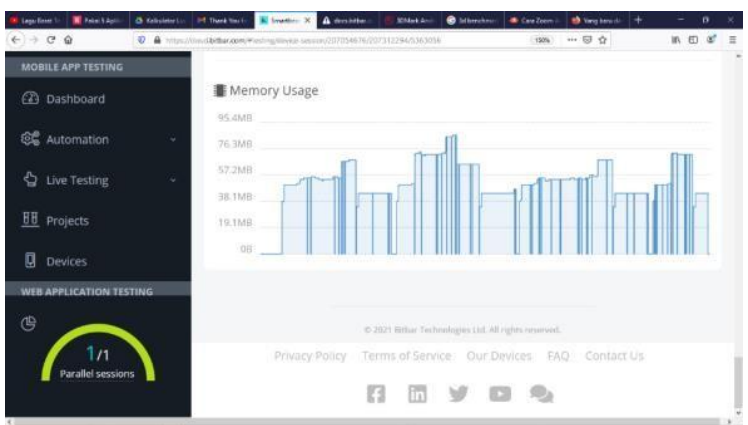

Penggunaan CPU maksimum berada diangka 9\% hal ini menunjukkan bahwa aplikasi telah memenuhi syarat aspek efficiency. Yaitu angka batas aman yang di tetapkan oleh Little Eye dengan rata-rata penggunaan CPU sebesar 15\% (mobileappanalysisttools). Adapun hasil dari pengujian CPU dapat dilihat pada gambar berikut.

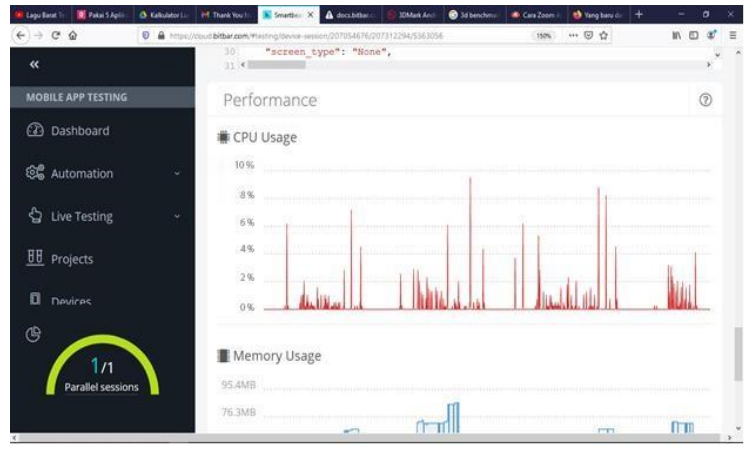

4. Aspek Maintainability

TABEL 4. PENGUJIAN MAINTAINABILITY

\begin{tabular}{|c|c|c|c|}
\hline No & Pernyataan & $\begin{array}{l}\text { Sub } \\
\text { Karakteristik }\end{array}$ & $\begin{array}{l}\text { Hasil Yang } \\
\text { Diharapkan }\end{array}$ \\
\hline 1 & $\begin{array}{l}\text { terdapat peringatan } \\
\text { pada aplikasi untuk } \\
\text { mengidentifikasikan } \\
\text { kesalahan }\end{array}$ & Analyzability & $\begin{array}{l}\text { Hasil yang } \\
\text { diperoleh dari } \\
\text { pengujian yang } \\
\text { telah dilakukan } \\
\text { menunjukkan } \\
\text { bahwa ketika } \\
\text { ada kesalahan } \\
\text { program atau } \\
\text { dalam } \\
\text { memasukkan } \\
\text { nilai pada } \\
\text { kalkulator, } \\
\text { maka aplikasi } \\
\text { akan } \\
\text { mengeluarkan } \\
\text { pesan peran } \\
\text { peringatan } \\
\text { error atau } \\
\text { aplikasi tidak } \\
\text { akan berjalan. }\end{array}$ \\
\hline 2 & $\begin{array}{l}\text { Kemudahan dalam } \\
\text { pengelolaan, } \\
\text { perbaikan, dan } \\
\text { pengembangan } \\
\text { aplikasi }\end{array}$ & Changebility & $\begin{array}{l}\text { Hasil yang } \\
\text { diperoleh dari } \\
\text { pengujian } \\
\text { menunjukkan } \\
\text { bahwa aplikasi } \\
\text { mudah untuk } \\
\text { diperbaikidan } \\
\text { dikembangkan } \\
\text { karena } \\
\text { menggunakan } \\
\text { software } \\
\text { android studio } \\
\text { yang mudah } \\
\text { digunakan dan } \\
\text { dikembangak } \\
\text { karena, } \\
\text { merupakan } \\
\text { pengembangan } \\
\text { aplikasi } \\
\text { android saat } \\
\text { ini. } \\
\text { Pengembang } \\
\text { tidak perlu } \\
\text { mengubah } \\
\text { keseluruhan } \\
\text { sistem dan ini } \\
\text { sangat } \\
\text { memudahkan } \\
\text { perbaikan }\end{array}$ \\
\hline
\end{tabular}


Pengujian aspek maintainability yang dilakukan adalah dengan menguji perangkat lunak pada aspek analiyzability dan changebility seperti pada Tabel diatas.

\section{Aspek Usability}

TABEL 5. HASIL PENGUJIAN USABILITY

\begin{tabular}{lllll}
\hline No & Interval & Kategori & $\begin{array}{l}\text { Jumlah } \\
\text { responden }\end{array}$ & $\begin{array}{l}\text { Persentase } \\
\text { Penilaian }\end{array}$ \\
\hline 1 & $>4.2$ & Sangat Baik & 19 & $95 \%$ \\
2 & $3,4-4,2$ & Baik & 1 & $5 \%$ \\
3 & $2,6-3,3$ & Cukup Baik & 0 & 0 \\
4 & $1,8-2,5$ & Kurang & 0 & 0 \\
& & Baik & & \\
5 & $<1,8$ & Tiak Baik & 0 & 0 \\
\hline
\end{tabular}

Berdasarkan tabel di atas diperoleh kesimpulan bahwa 19 orang responden atau 95\% memberi penilaian sangat baik, 1 orang responden atau $5 \%$ memberi penilaian baik dan tidak ada responden memberi penilaian cukup baik, kurang baik dan sangat tidak baik

\section{B. Pembahasan}

Hasil penelitian yang dilakukan menghasilkan aplikasi kalkulator penghitung luminansi berbasis android. Aplikasi kalkulator penghitung luminansi ini adalah aplikasi yang berjalan pada perangkat android. Perancangan aplikasi ini bertujuan untuk memudahkan pengguna yaitu masyarakat umum, dalam menentukan jumlah kuat penerangan yang akan mereka gunakan.

Aplikasi kalkulator penghitung luminansi ini dibangun dengan menggunakan metode pengembangan prototype. Prototype merupakan salah satu metode pengembangan perangkat lunak yang banyak digunakan. Pada tahap pengumpulan kebutuhan, pengembang mendefiniskan format dan kebutuhan keseluruhan perangkat lunak, mengidentifikasi semua kebutuhan, dan garis besar sistem yang akan dibuat. Software yang digunakan adalah Android Studio dan Photoshop CS6.

Pada tahap perancangan Prototype, pengembang membuat desain awal aplikasi yang menjabarkan apa saja yang dapat dilakukan pengguna terhadap aplikasi. Jika desain awal telah sesuai seperti yang diinginkan, maka flowchart yang telah dibuat dijadikan sebagai dasar pembuatan program. Pengujian adalah proses mengeksekusi program secara intensif untuk menemukan kesalahan-kesalahan. Pengujian tidak hanya untuk mendapatkan program yang benar, namun juga memastikan bahwa program tersebut bebas dari kesalahan- kesalahan untuk segala kondisi.

Pengujian aspek functionality adalah tingkat seberapa jauh fungsi-fungsi yang ada pada sistem dapat diimplementasikan dan berjalan sesuai dengan yang diharapkan. Pengujian functionality dilakukan dengan menggunakan checklist yang diberikan oleh ahli media. Pengujian aspek portability adalah kemampuan aplikasi untuk ditransfer dari satu lingkungan ke lingkungan lain. Pengujian ini dil;akukan terhadap versi android dan resolusi pada handphone yang berbeda. Namun, penggunaan software ini sangat sulit di akses dan membutuhkan banyak persyaratan yang sulit dijangkau oleh peneliti. Sehingga dipilihlah software yang lebih mudah untuk dijangkau yaitu Cloud.bitbar.

Berdasrkan dua sub-karakteristik yang digunakan, dianggap telah memenuhi dikarenakan kemampuan aplikasi untuk direvisi dan aplikasi yang bersifat multitasking dalam merespon ketika ada kesalahan. Pengujian usability adalah kemampuan yang berhubungan dengan penggunaan perangkat lunak, kemudahan dalam menggunakan fungsifungsi yang diberikan serta kemudahan mempelajari

\section{KESIMPULAN}

Kesimpulan dari penlitian Pengembangan Aplikasi Kalkulator Penghitung Luminansi Berbasis Android sebagai berikut :

1. Pengembangan aplikasi Kalkulator Penghitung Luminansi Berbasis Android dengan menggunakan model pengembangan prototyping yang terdiri atas tujuh langkah yaitu pengumpulan kebutuhan, membangun prototyping, evaluasi prototyping, pengkodean sistem, menguji sistem, evaluasi sistem dan menggunakan sistem. Aplikasi ini dikembangkan menggunakan software Android Studio dengan bahasa pemrograman java. Hasil pengembangan adalah aplikasi Kalkulator Lumenansi berbasis Android yang diakses secara offline.

2. Kualitas aplikasi Kalkulator Luminansi berbasis Android berdasarkan standar kualitas ISO 25010 telah terpenuhi dengan hasil : a) pengujian aspek functionality yang telah memenuhi aspek dari dua ahli sistem; b) pengujian aspek efficiency yang menghasilkan kualitas memenuhi berdasarkan little ey; c) pengujian aspek portability pada beberapa jenis smarthphone berjalan dengan baik; d) pengujian aspek maintainability telah memenuhi berdasarkan jenis software yang digunakan; e) pengujian aspek usability berada pada kategori sangat baik.

\section{DAFTAR PUSTAKA}

[1] K. K. R. Indonesia, "Keputusan Menteri Kesehatan Republik Indonesia No: 1405/MENKES/SK/XI/2002 tentang Persyaratan 
Kesehatan Lingkungan Kerja Perkantoran dan Industri," Kementrian Kesehatan Republik Indonesia, Jakarta, 2002.

[2] A. G. K. Djupri, M. S. Hardjanto, S. OK, and M. K. Suwaji, "Pengaruh Intensitas Penerangan Terhadap Kelelahan Mata pada Siswa Kelas IV dan V Sekolah Dasar Negeri 02 Kuripan-Purwodadi," Universitas Muhammadiyah Surakarta, 2013.

[3] P. K. Suma'mur, "Hygiene Perusahaan \& Keselamatan Kerja," Jakarta: Gunung Agung, 2009.

[4] H. Heni and A. J. Mujahid, "Pengaruh Penggunaan Smartphone terhadap Perkembangan Personal Sosial Anak Usia Pra-Sekolah," Jurnal Keperawatan Silampari, vol. 2, no. 1, pp. 330-342, 2018.

[5] A. G. Hunt and R. E. Garforth, "Luminous efficiency meter for electric arcs," Optics Technology, vol. 2, no. 2, pp. 99-101, 1970.

[6] A. Yulianty and A. Kurniawati, "Quality Analysis of Bios Portal Website at Banking Companies Using ISO/IEC 25010: 2011 Method".

[7] R. Ruslan, E. S. Rahman, and D. Vitalocca, "Pengembangan Sistem Penilaian Kenaikan Pangkat Dosen Pada Jurusan Pendidikan Teknik Elektro Universitas Negeri Makassar," Jurnal Media Elektrik, vol. 18, no. 3, pp. 14-19, 2021. 